\title{
Validation of a Spanish version of the Revised Fibromyalgia Impact Questionnaire (FIQR)
}

\author{
Monika Salgueiro', Juan Miguel García-Leiva², Javier Ballesteros ${ }^{1,3}$, Javier Hidalgo², Rocío Molina ${ }^{2}$ \\ and Elena P Calandre
}

\begin{abstract}
Background: The Revised version of the Fibromyalgia Impact Questionnaire (FIQR) was published in 2009. The aim of this study was to prepare a Spanish version, and to assess its psychometric properties in a sample of patients with fibromyalgia.

Methods: The FIQR was translated into Spanish and administered, along with the FIQ, the Hospital Anxiety Depression Scale (HADS), the 36-Item Short-Form Health Survey (SF-36), and the Brief Pain Inventory (BPI), to 113 Spanish fibromyalgia patients. The administration of the Spanish FIQR was repeated a week later.

Results: The Spanish FIQR had high internal consistency (Cronbach's a was 0.91 and 0.95 at visits 1 and 2 respectively). The test-retest reliability was good for the FIQR total score and its function and symptoms domains (intraclass correlation coefficient (ICC $>0.70$ ), but modest for the overall impact domain (ICC $=0.51$ ). Statistically significant correlations $(p<0.05)$ were also found between the FIQR and the FIQ scores, as well as between the FIQR scores and the remaining scales' scores.
\end{abstract}

Conclusions: The Spanish version of the FIQR has a good internal consistency and our findings support its validity for assessing fibromyalgia patients. It might be a valid instrument to apply in clinical and investigational grounds.

Keywords: Fibromyalgia, Revised fibromyalgia impact questionnaire, Linguistic validation, Psychometric properties, Instrumental study

\section{Resumen}

Antecedentes: El Cuestionario de Impacto de Fibromialgia ( $F \mid Q$ ) ha sido utilizado como medida de valoración en numerosos estudios clínicos. En 2009 se publicó en inglés su versión revisada (FIQR). El presente estudio se llevó a cabo para traducir al español y validar dicha versión.

Pacientes y Método: La traducción fue realizada por dos de los autores. La versión traducida del FIQR se administró a 113 pacientes con fibromialgia junto con el FIQ, la Escala Hospitalaria de Ansiedad y Depresión, el Cuestionario de Salud SF-36 y la versión abreviada del Cuestionario Breve de Dolor. Una semana después se administró de nuevo el FIQR. Su consistencia interna se evaluó mediante el coeficiente a de Cronbach. Se calcularon los coeficientes de correlación intraclase (ICC) entre las puntaciones de la nueva versión y la anterior, así como las subescalas del Cuestionario SF-36, de la Escala Hospitalaria de Ansiedad y Depresión y del Inventario Breve de Dolor. La fiabilidad test-retest se evaluó igualmente mediante coeficientes de correlación intraclase.

\footnotetext{
* Correspondence: calandre@gmail.com

${ }^{2}$ Institute of Neurosciences, University of Granada, Granada, Spain

Full list of author information is available at the end of the article
} 


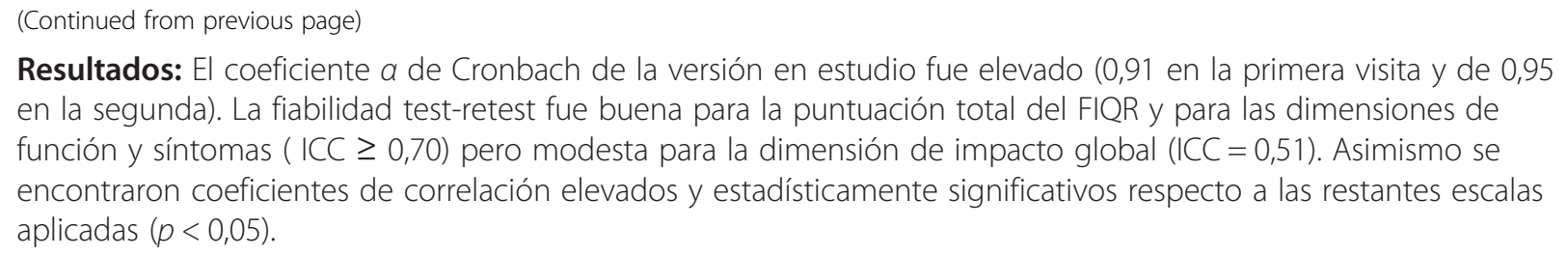

Conclusión: La versión española del FIQR es un instrumento válido para su uso en la evaluación e investigación clínicas.

Palabras clave: Fibromialgia, Cuestionario de impacto de fibromialgia revisado, Validación lingüística, Propiedades psicométricas, Estudio instrumental

\section{Background}

Fibromyalgia syndrome (FMS) is a chronic musculoskeletal disorder characterized by widespread and diffuse pain, often accompanied by fatigue, sleep disturbances, and depressed mood [1]. It significantly impairs the quality of life of the patients and can be highly disabling [2]. Since neither diagnostic laboratory tests nor specific radiological findings are available for its diagnosis, the assessment of pain severity and accompanying symptoms is considered essential on this regard, as well as its impact on the functional capacity and the quality of life of FMS patients. Burckhardt et al. [3] developed and published a tool to measure the impact of FMS symptoms on daily living abilities and general health status, the Fibromyalgia Impact Questionnaire (FIQ). The authors' purpose was to take into account not only the pain, but also symptoms such as restless sleep, fatigue, muscular stiffness, anxiety, or depression, and their impact on perceived quality of life in the previous week.

The FIQ has been translated and validated in 14 different languages, and has been used as an outcome measure in more than 300 research papers. In fact, it is considered the most sensitive method to evaluate the clinical course of the FMS as well as its response to treatment in clinical trials [4-6]. The questionnaire, however, has been criticized, mainly due to the cumbersome scoring algorithm used, and the absence of important issues such as cognitive impairment, postural balance, or environmental sensitivity [7].

In response to such criticisms, Bennett and his colleagues published, in 2009, a revised version of the questionnaire, the FIQR [8]. The improved proposed tool disposes of the Likert items and the visual analogue scales, and assesses the severity of symptoms in using discrete values shown in 11 boxes, valued from 0 to 10 , with 10 being 'worst'. Furthermore, it includes a wider range of symptoms associated with FMS, such as tenderness to touch, memory disorders, postural balance, hyperalgesia, or sensitivity to environmental factors. Some of the questions, originally intended for women living in reasonably affluent income countries in a previous FIQ, were reformulated to be suitable for both men and women of all socioeconomic levels. As in the previous version of the FIQ, all questions relate to the impact of FMS over the course of the past 7 days.

The FIQR has recently been validated and translated into Turkish [9] and to Arabian Moroccan [10]. The authors of this study undertook a translation of the FIQR (Appendix A) that was used in a previous study on the risk of suicide in FMS patients [11]. The aim of this paper was to test the reliability (internal and test-retest) and construct validity of the Spanish version of the FIQR.

\section{Materials and methods \\ Participants}

Subjects were recruited from several associations of FMS patients of different Spanish provinces. To be included in the study, patients had to fulfill the American College of Rheumatology criteria for FMS published in 1990 [1]. The only exclusion criterion was a medical, psychiatric, or cognitive disorder that impeded the patient's ability to correctly answer the Case Report Form (CRF). In order to include a representative sample of Spanish FMS patient, age and comorbidity were not considered as exclusion criteria.

Those patients who volunteered to participate were given for completion a CRF that included sociodemographic data, the proposed Spanish version of the Revised Fibromyalgia Impact Questionnaire (FIQR), the validated Spanish versions of the original FIQ, the Hospital Anxiety and Depression Scale (HADS), the Short Form 36 Health Survey (SF-36), and the Brief Pain Inventory (BPI). All patients completed these instruments on the day of the visit, and one week later participants were reappraised by using only the FIQR.

The study protocol was approved by the Human Research Ethics Committee of the University of Granada, and all the patients signed a consent form attesting their willingness to participate in the study.

\section{Assessment tools}

Fibromyalgia Impact Questionnaire (FIQ)

The FIQ [3] is a 10-item self-report questionnaire developed to measure both physical and psychological symptoms of FMS, and their interference in daily living tasks and in 
perceived quality of life by patients. The first item uses 4-point Likert scales for assessing patients' ability to carry out physical activities over the course of the past 7 days. Items 2 and 3 indicate the number of days in the former week that the patients felt good, and how many days of work they missed. Finally, the remaining seven questions use a 10-centimeter visual analogue scale in order to measure patients' disability at work, and severity of pain, fatigue, morning tiredness, muscular stiffness, anxiety, and depression. The questionnaire scoring procedure requires recoding of item 3 , and standardizing raw scores for calculating the arithmetic mean value ranging from 0 (lowest impact) to 10 (maximum impact). The consensus version [12] made from the different Spanish FIQ forms was used.

\section{Revised Fibromyalgia Impact Questionnaire (FIQR)}

The FIQR [8] is a 21-item self-administered questionnaire. All items are visual analogue scales with 11 boxes discreetly scoring from 0 to 10 . From the direct answers three linked sets of domains can be calculated: (i) function, which is the sum of the first 9 items divided by 3 , and can take a value between 0 and 30; (ii) overall impact, which is the sum of the items 10 and 11, and can take a value between 0 and 20; and (iii) symptoms, which is calculated by adding the raw score of the items from 12 to 21 divided by 2 , and can take a value between 0 and 50. The total FIQR, whose maximal score is 100 , is the sum of the three domain scores, and represents the overall impact of symptoms on quality of life.

The Spanish translation of the original questionnaire was performed and agreed by two bilingual authors of the study (EPC and JMGL) [See Additional file 1].

\section{Hospital Anxiety and Depression Scale (HADS)}

The Hospital Anxiety and Depression Scale (HADS) [13] is commonly used to determine the levels of anxiety and depression that a patient is experiencing. This scale specifically avoids reliance on aspects of these conditions that are also common to somatic symptoms or illness, such as fatigue or insomnia, so that it is very useful in the assessment of anxiety and depression in patients with physical illness. It is a 14-item scale, seven of the items related to anxiety and seven related to depression. Each item is scored from 0 to 3 by using a Likert scale. Overall rates of either anxiety or depression can take values comprised between 0 and 21, with higher scores indicative of greater severity of symptoms. The validated Spanish version [14] was used.

\section{Short Form (36) Health Survey (SF-36)}

The Short Form (36) Health Survey (SF-36) [15] provides a profile of health status and is often used to assess the health related quality of life [16]. The questionnaire consists of eight subscales: vitality, physical functioning, bodily pain, general health perception, physical role functioning, emotional role functioning, social role functioning, and mental health, which are the weighted sums of the questions in their section. Each scale is directly transformed into a 0-100 scale on the assumption that each question carries equal weight. Therewith, two global domains of health can be calculated, named Physical Component Summary (PCS) and Mental Component Summary (MCS). In all subscales and domains higher scores refer to better health status. The Spanish version of SF-36 adapted by Alonso and collaborators [17] was used.

\section{Brief Pain Inventory (BPI)}

The Brief Pain Inventory (BPI) [18] is a validated, widely used, self-administered instrument developed to assess pain interference with daily functions [19]. It uses visual analogue scales ranging from 0 to 100 to measure both the intensity of the pain (sensory dimension) and its interference with the patient's life (reactive dimension). It also queries the patient about pain relief, pain quality, and patient perception of the cause of pain. The validated Spanish version of BPI [20] was used.

\section{Statistics}

Demographic data were analyzed using the descriptive statistics of mean, standard deviation (SD) and range. Age and duration of pain were used as continuous variables. The remaining variables were used as dichotomous ones and described using the absolute and relative frequencies.

Test-retest reliability was assessed using the intraclass correlation coefficients (ICC) between the FIQR scores of the first and the 1-week follow-up evaluations. We used a two-way random effect model to estimate the ICC and 95\% confidence intervals (CI) [21]. Internal consistency was determined using Cronbach's $\alpha$ coefficient. Construct validity was evaluated with Pearson's $r$ correlation coefficients correlating the FIQR total score with the former FIQ, the HADS, and the BPI for convergent validity, and with the SF-36 for divergent validity. Guided by previous research on FIQR validations $[9,10]$ we expected to find internal consistency values (Cronbach's $\alpha) \geq 0.80$, test-retest reliability values (ICC) $\geq 0.70$, and convergent and divergent validity values showing at least moderate to important correlations between the FIQR and the target scales (Pearson's $r$ values in the range of 0.40 to $0.70)$. Given these values we estimated that sample sizes in the range of 20 to 60 subjects would be sufficient to estimate correlations between 0.40 and 0.70 assuming a $5 \%$ as significance level and $90 \%$ power.

Statistical analyses were conducted with the SPSS v17.0 (Chicago, IL, USA) and Stata v12 (College Station, TX, USA) 


\section{Results}

One hundred and fourteen patients completed the questionnaires: one of these was excluded because of missing items. Thus, the study sample consisted of 113 patients. Their sociodemographic characteristics are shown in Table 1.

Table 2 shows the main descriptive statistics for the FIQR at the test and retest visits one week apart as well as the ICC to estimate the temporal stability of the measurements. The studied sample showed a FIQ total score of 70.15 (SD: 17.82). Histograms of distributions of FIQ and FIQR total scores are shown in Figure 1. Cronbach's $\alpha$ calculation for the Spanish version of FIQR was 0.91 in the first visit, and 0.95 in the second visit.

The response of the Spanish version of FIQR provided in the second visit showed a satisfactory temporal stability on the dimensions assessed by the total FIQR $(\mathrm{ICC}=0.82$, $95 \% \mathrm{CI}=0.75$ to 0.87 ), the FIQR function ( $\mathrm{ICC}=0.73$, $95 \% \mathrm{CI}=0.63$ to 0.80 ), and the FIQR symptoms (ICC $=0.81$, $95 \% \mathrm{CI}=0.73$ to 0.87 ). On the contrary the dimension of FIQR overall impact showed a low temporal stability $(\mathrm{ICC}=$ $0.51,95 \% \mathrm{CI}=0.36$ to 0.63 ). Three items of the FIQR function presented an ICC point estimate below 0.70 ("prepare a meal", "clean floors", and "carry a bag of groceries") and the item "go shopping for groceries" presented a significant time effect ( $\mathrm{p}<0.05$ for the mean difference between visits). The 2 items of the FIQR overall impact presented an ICC below 0.70. Four items of the FIQR symptoms presented an ICC below 0.70 ("pain rating", "energy rating", "stiffness rating", and "sleep quality"), whereas the test-retest ratings for FIQR symptoms, stiffness, and memory problems showed a significant time effect $(\mathrm{p}<0.05)$.

Table 1 Sociodemographics of fibromyalgia syndrome patients $(\mathrm{N}=113)$

\begin{tabular}{lc}
\hline & [N (\%)] \\
\hline Gender & $109(96.5)$ \\
- Female & $4(3.5)$ \\
- Male & $51.6 \pm 9.6$ \\
Age in years (mean \pm SD) & \\
Marital status: & $23(21.5)$ \\
- Unmarried & $67(62.6)$ \\
- Married & $13(12.2)$ \\
- Divorced & $3(2.8)$ \\
- Widowed & \\
Education: & $9(8.0)$ \\
- lliterate & $51(45.5)$ \\
- Primary & $37(33.0)$ \\
- Secondary & $14(12.5)$ \\
- Tertiary & $8.5 \pm 7.6$ \\
Disease duration in years (mean \pm SD)
\end{tabular}

Table 2 Test-retest reliability of the Revised Fibromyalgia Impact Questionnaire total, dimensions, and individual items scores

\begin{tabular}{|c|c|c|c|}
\hline & $\begin{array}{c}\text { Visit } 1 \\
(\text { mean } \pm \text { SD) }\end{array}$ & $\begin{array}{c}\text { Visit } 2 \\
\text { (mean } \pm \text { SD) }\end{array}$ & $\begin{array}{c}\text { ICC } \\
(95 \% \mathrm{Cl})\end{array}$ \\
\hline FIQR total & $68.2 \pm 17.5$ & $67.4 \pm 19.9$ & $\begin{array}{c}0.82 \\
(0.75 \text { to } 0.87)\end{array}$ \\
\hline FIQR function & $18.9 \pm 6.7$ & $19.2 \pm 6.8$ & $\begin{array}{c}0.73 \\
(0.63 \text { to } 0.80)\end{array}$ \\
\hline Comb hair & $4.48 \pm 2.9$ & $4.56 \pm 3.1$ & $\begin{array}{c}0.72 \\
(0.62 \text { to } 0.80)\end{array}$ \\
\hline Walk for 20 minutes & $5.70 \pm 3.4$ & $5.75 \pm 3.5$ & $\begin{array}{c}0.74 \\
(0.64 \text { to } 0.81)\end{array}$ \\
\hline Prepare a meal & $4.57 \pm 3.0$ & $5.22 \pm 3.1$ & $\begin{array}{c}0.66 \\
(0.54 \text { to } 0.75)\end{array}$ \\
\hline Clean floors & $6.90 \pm 2.8$ & $7.16 \pm 2.7$ & $\begin{array}{c}0.60 \\
(0.47 \text { to } 0.71)\end{array}$ \\
\hline $\begin{array}{l}\text { Carry a bag of } \\
\text { groceries }\end{array}$ & $8.23 \pm 6.4$ & $7.59 \pm 2.7$ & $\begin{array}{c}0.19 \\
(0.01 \text { to } 0.36)\end{array}$ \\
\hline Climb a flight of stairs & $7.16 \pm 2.6$ & $7.25 \pm 2.8$ & $\begin{array}{c}0.70 \\
(0.60 \text { to } 0.79)\end{array}$ \\
\hline Change bed sheets & $6.73 \pm 2.5$ & $6.66 \pm 2.6$ & $\begin{array}{c}0.74 \\
(0.65 \text { to } 0.82)\end{array}$ \\
\hline Sit for 45 minutes & $6.74 \pm 2.8$ & $6.72 \pm 2.9$ & $\begin{array}{c}0.70 \\
(0.59 \text { to } 0.78)\end{array}$ \\
\hline $\begin{array}{l}\text { Go shopping for } \\
\text { groceries }\end{array}$ & $6.36 \pm 2.8$ & $6.81 \pm 2.6$ & $\begin{array}{c}0.73 \\
(0.63 \text { to } 0.81)\end{array}$ \\
\hline FIQR overall impact & $11.8 \pm 5.6$ & $12.0 \pm 5.9$ & $\begin{array}{c}0.51 \\
(0.36 \text { to } 0.63)\end{array}$ \\
\hline Can not achieve goals & $5.91 \pm 2.9$ & $5.98 \pm 3.0$ & $\begin{array}{c}0.59 \\
(0.45 \text { to } 0.69)\end{array}$ \\
\hline Feel overwhelmed & $5.88 \pm 3.3$ & $6.05 \pm 3.1$ & $\begin{array}{c}0.37 \\
(0.20 \text { to } 0.52)\end{array}$ \\
\hline FIQR symptoms & $37.5 \pm 8.7$ & $36.1 \pm 9.6$ & $\begin{array}{c}0.81 \\
(0.73 \text { to } 0.87)\end{array}$ \\
\hline Pain rating & $7.73 \pm 2.2$ & $7.65 \pm 2.2$ & $\begin{array}{c}0.64 \\
(0.52 \text { to } 0.74)\end{array}$ \\
\hline Energy rating & $7.73 \pm 2.3$ & $7.72 \pm 2.2$ & $\begin{array}{c}0.63 \\
(0.50 \text { to } 0.73)\end{array}$ \\
\hline Stiffness rating & $7.39 \pm 2.2$ & $6.91 \pm 2.6$ & $\begin{array}{c}0.69 \\
(0.57 \text { to } 0.78)\end{array}$ \\
\hline Sleep quality & $8.62 \pm 2.1$ & $8.26 \pm 2.1$ & $\begin{array}{c}0.52 \\
(0.38 \text { to } 0.64)\end{array}$ \\
\hline Depression level & $6.54 \pm 3.2$ & $6.47 \pm 3.2$ & $\begin{array}{c}0.87 \\
\text { (0.82 to 0.91) }\end{array}$ \\
\hline Memory problems & $7.53 \pm 2.5$ & $7.14 \pm 2.5$ & $\begin{array}{c}0.78 \\
(0.69 \text { to } 0.84)\end{array}$ \\
\hline Anxiety level & $7.18 \pm 2.8$ & $6.71 \pm 2.9$ & $\begin{array}{c}0.80 \\
(0.72 \text { to } 0.86)\end{array}$ \\
\hline Tenderness level & $7.43 \pm 2.7$ & $7.28 \pm 2.9$ & $\begin{array}{c}0.76 \\
(0.68 \text { to } 0.83)\end{array}$ \\
\hline Balance problems & $6.95 \pm 2.5$ & $6.49 \pm 2.5$ & $\begin{array}{c}0.70 \\
(0.59 \text { to } 0.79)\end{array}$ \\
\hline $\begin{array}{l}\text { Environmental } \\
\text { sensitivity }\end{array}$ & $8.02 \pm 2.2$ & $7.67 \pm 2.3$ & $\begin{array}{c}0.71 \\
(0.61 \text { to } 0.80)\end{array}$ \\
\hline
\end{tabular}

SD Standard Deviation, ICC intraclass correlation coefficient, 95\% Cl 95\% confidence interval, FIQR Fibromyalgia Impact Questionnaire Revised. 

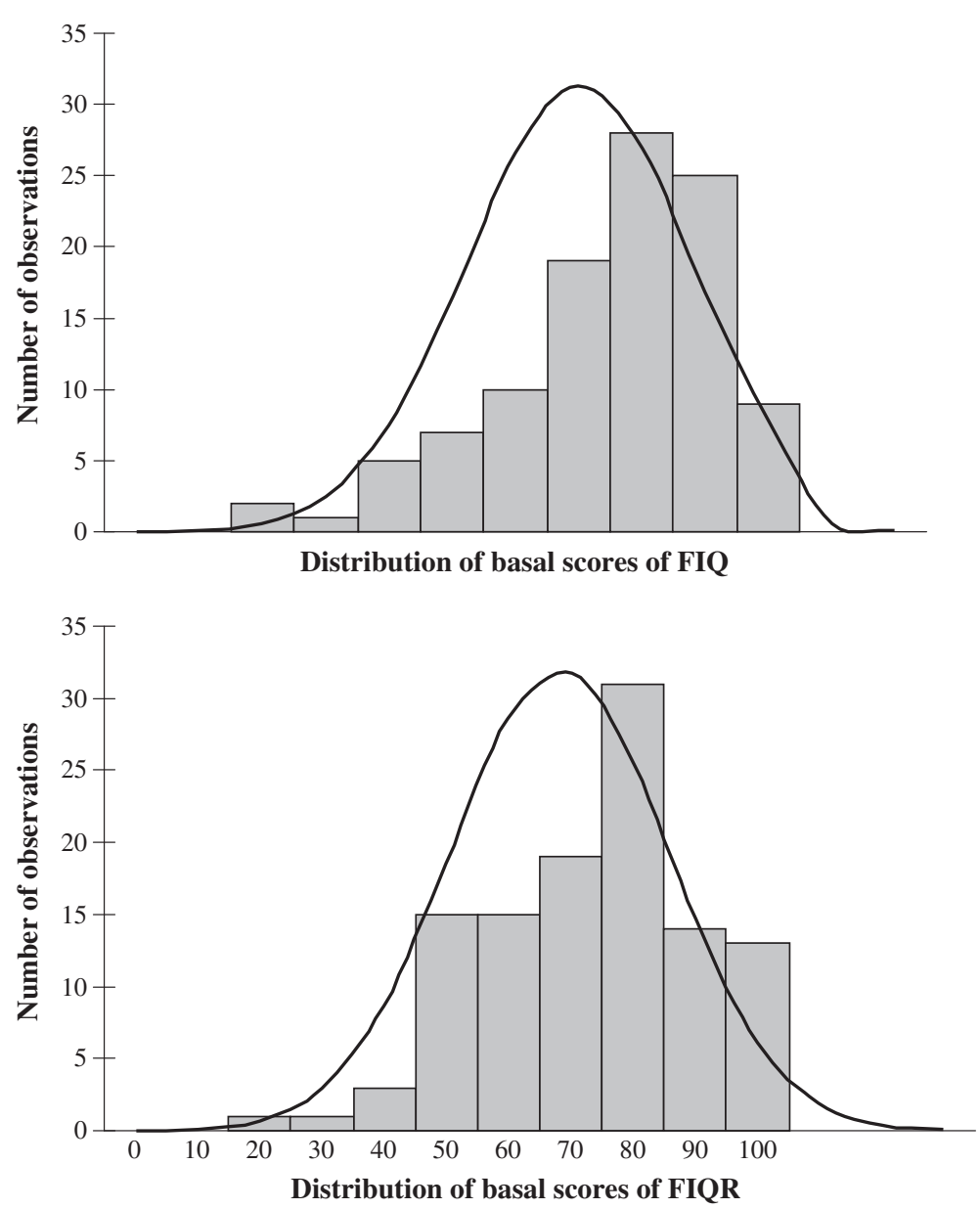

Figure 1 Histograms of FIQ and FIQR showing distribution of basal scores.

Pearson's $r$ correlations coefficients between FIQR total, function, overall impact, and symptoms scores, and study questionnaires were calculated for testing construct validity according to convergent and divergent validity criteria (Table 3). The total scores of the FIQR and FIQ were closely correlated $(r=0.83, p<0.01)$. The FIQR total, function, overall impact, and symptoms scores showed significant correlations with HADS depression and anxiety subscales, pain intensity and its interference with daily activities assessed by using BPI ( $p<0.01$ in every case). Finally, significant $(p<0.01)$ inverse correlations were also found between FIQR total and its domains' scores, and quality of life assessed by SF-36 (Table 3).

\section{Discussion}

Overall, our findings suggest that the FIQR is a sufficiently reliable and valid measure of health status in Spanish patients of FMS.

The sample of patients with FMS in this study presents the expected demographic and clinical characteristics of the disorder: middle-aged women, married and with primary studies, and with several years of duration of the disease (Table 1). The duration of pain and symptoms of FMS were highly variable, probably due to the wide age range (3087 years) of studied sample.

Participants reported similar scores of FIQR in both evaluations (68.22, SD: 17.5 and 67.42, SD: 19.89, in the first and the second visit, respectively). These values are consistent with those obtained by Srifi and collaborators [10] (65, SD: 14.5 for the first visit, and 63.2, SD: 16.6 for the second visit), and are slightly higher than those published by Ediz and his colleagues [9] (55.22, SD: 21.96 and 57.16, SD: 22.48, respectively).

The psychometric properties of the Spanish FIQR in patients with FMS were similar both to those of the original English-language validation study [8] and the two subsequent Turkish [9] and Arabic Moroccan [10] validations. Internal consistency of the Spanish FIQR was found as high as 0.91 for the first visit and 0.95 for the second visit, indicating acceptable levels of internal consistency for both assessments. This level of internal consistency of the Spanish FIQR is close to the one of 
Table 3 Revised Fibromyalgia Impact Questionnaire total and dimensions scores construct validity (Pearson's correlation coefficients and $95 \% \mathrm{CI}$ )

\begin{tabular}{|c|c|c|c|c|}
\hline & FIQR total & FIQR function & FIQR overall & FIQR symptoms \\
\hline FIQ total & 0.83 (0.75 to 0.88$)$ & 0.68 (0.56 to 0.77$)$ & 0.47 (0.31 to 0.61$)$ & 0.83 (0.76 to 0.88$)$ \\
\hline HADS total & 0.69 (0.57 to 0.77$)$ & 0.53 (0.38 to 0.66$)$ & 0.45 (0.28 to 0.58$)$ & 0.70 (0.59 to 0.79$)$ \\
\hline HADS anxiety & $0.66(0.54$ to 0.75$)$ & $0.50(0.35$ to 0.63$)$ & $0.42(0.25$ to 0.56$)$ & 0.68 (0.56 to 0.77$)$ \\
\hline HADS depression & 0.62 (0.49 to 0.72 ) & $0.46(0.30$ to 0.60$)$ & 0.39 (0.22 to 0.54$)$ & 0.65 (0.53 to 0.75$)$ \\
\hline BPI severity & 0.70 (0.57 to 0.78$)$ & 0.51 (0.36 to 0.64$)$ & $0.46(0.31$ to 0.61$)$ & 0.68 (0.56 to 0.77$)$ \\
\hline BPI interference & 0.84 (0.78 to 0.89$)$ & 0.68 (0.57 to 0.77$)$ & 0.49 (0.33 to 0.62$)$ & 0.85 (0.79 to 0.89$)$ \\
\hline \multicolumn{5}{|l|}{ SF-36: } \\
\hline Physical Component Summary (PCS) & $-0.53(-0.65$ to -0.38$)$ & $-0.48(-0.61$ to -0.32$)$ & $-0.33(-0.49$ to -0.16$)$ & $-0.48(-0.61$ to -0.32$)$ \\
\hline Mental Component Summary (MCS) & $-0.65(-0.75$ to -0.53$)$ & $-0.47(-0.60$ to -0.31$)$ & $-0.41(-0.55$ to -0.24$)$ & $-0.68(-0.77$ to -0.56$)$ \\
\hline Physical functioning (PF) & $-0.68(-0.77$ to -0.57$)$ & $-0.64(-0.74$ to -0.52$)$ & $-0.35(-0.50$ to -0.17$)$ & $-0.64(-0.74$ to -0.52$)$ \\
\hline Physical role functioning (PR) & $-0.43(-0.57$ to -0.26$)$ & $-0.32(-0.47$ to -0.14$)$ & $-0.32(-0.48$ to -0.14$)$ & $-0.41(-0.55$ to -0.24$)$ \\
\hline Bodily pain (BP) & $-0.70(-0.79$ to -0.60$)$ & $-0.55(-0.67$ to -0.40$)$ & $-0.45(-0.59$ to -0.29$)$ & $-0.70(-0.78$ to -0.59$)$ \\
\hline General health perceptions (GH) & $-0.63(-0.73$ to -0.50$)$ & $-0.46(-0.60$ to -0.30$)$ & $-0.41(-0.56$ to -0.25$)$ & $-0.64(-0.74$ to -0.51$)$ \\
\hline Vitality (VT) & $-0.71(-0.79$ to -0.60$)$ & $-0.55(-0.67$ to -0.41$)$ & $-0.45(-0.59$ to -0.29$)$ & $-0.70(-0.78$ to -0.59$)$ \\
\hline Social role functioning (SF) & $-0.65(-0.74$ to -0.52$)$ & $-0.50(-0.63$ to -0.35$)$ & $-0.44(-0.57$ to -0.27$)$ & $-0.63(-0.73$ to -0.50$)$ \\
\hline Emotional role functioning (RE) & $-0.54(-0.66$ to -0.40$)$ & $-0.40(-0.55$ to -0.24$)$ & $-0.33(-0.49$ to -0.16$)$ & $-0.56(-0.68$ to -0.42$)$ \\
\hline Mental health (MH) & $-0.69(-0.78$ to -0.58$)$ & $-0.51(-0.64$ to -0.36$)$ & $-0.41(-0.56$ to -0.25$)$ & $-0.72(-0.80$ to -0.61$)$ \\
\hline
\end{tabular}

95\% CI 95\% confidence interval, FIQR Fibromyalgia Impact Questionnaire Revised, FIQ Fibromyalgia Impact Questionnaire, HADS Hospital Anxiety and Depression Scale, BPI Brief Pain Inventory, SF-36 Short Form Health Survey.

Bennett et al. [8], who obtained internal consistency of 0.95 , and similar than those published by both Turkish $(\alpha=0.89$ in the first visit, and $\alpha=0.91$ in the second visit) [9], and Moroccan teams ( $\alpha=0.91$ in the first visit, and $\alpha=0.94$ in the second visit) [10].

The test-retest reliability of the FIQR total score evaluated with the ICC was 0.82 (Table 2), close to those obtained in the Turkish $(r=0.84)$ [9] and Moroccan $(r=0.84)$ [10] versions. No test-retest reliability of the original FIQR was performed by Bennett et al. [8].

Considering separately the three FIQR domains, symptoms showed adequate test-retest reliability $(\mathrm{ICC}=0.81)$, as well as function (ICC $=0.73$ ). However, overall impact performed somewhat lower $(\mathrm{ICC}=0.51,95 \% \mathrm{CI}=0.36$ to 0.63 ), and thus point to the possibility of improvement in that domain measure. This could be due to the high variability showed by FMS patients in terms achievement goals and overwhelmed feeling and their impact in daily activities. Although the general reproducibility of the Spanish FIQR was good, the test-retest reliability of some individual items, with ICC values that varied between 0.19 and 0.87 , was lower than those obtained by the other validated versions of FIQR, those had Spearman's rho $>0.70[9,10]$. Of course this is not unexpected since neither Pearson's $r$ nor Spearman's rho as association measures do take systematic errors for individual measurements over time into account, and thus could lead to overestimate the temporal reliability of a measurement [22]. Future uses of the Spanish FIQR, should consider the reformulation of some of the items that obtained lower reliability indexes and significant time effect over the one-week period for test-retest reliability.

Construct validity, both convergent and divergent, of Spanish translation of FIQR was evidenced by the significant correlations found between the FIQR total and domains scores with all the questionnaires used in the validation process (Table 3). As expected, and as observed in previous studies [8-10], both the total FIQR and its domains showed a good correlation with the FIQ, the HADS, the BPI and the SF-36 scores. A noticeable correlation between FIQR and previous FIQ $(r=0.83, p<0.01)$ and the similar distribution of their scores (Figure 1), makes it possible to compare the results of studies using the older version with studies using the revised version [8].

According to Bennet et al. [8], the FIQR has sound psychometric properties, discriminates between FMS patients, and patients with rheumatoid arthritis, systemic lupus erythematosus, or major depression disorder. Moreover, FIQR provides advantages over the previous version. The use of a numeric rating scale using 11 boxes, scored 0 to 10 in the FIQR as opposed to the combination of Likert and visual analogue scaling in the FIQ, considerably simplifies the scoring algorithm for the FIQR and obviates the need to use a ruler to measure visual analogue scales scores. This simplification and greater efficiency should make the FIQR easier to use by researchers and physicians. In our experience, the FIQR is substantially easier to use than the FIQ. The scoring system is much easier to 
perform and this facilitates its use not only by investigators but also in clinical grounds. Also, the substitution of the question "How have you felt when you get up in the morning?" by "Please rate the quality of your sleep" clarifies this question for the patients. In relation to the new added items, patients rated these symptoms in a similar range than the older ones; this means that they are present in most patients with fibromyalgia and, therefore, that they needed to be recorded, making this extension a welcome addition.

One of the limitations of our study is the fact that patients were recruited from fibromyalgia patients' associations; this probably excluded less affected patients that frequently are not part of these associations. Also, our study did not assess some psychometric properties of the questionnaire, such as the sensitivity to change over time both with and without treatment. Finally, although patients were recruited in different parts of Spain in order ensure both a geographic and cultural diversity, it was not representative of every Spanish region.

\section{Conclusions}

Despite the above mentioned limitations, we think that the Spanish FIQR can be currently considered a valid, usable and reliable tool for the assessment of Spanish-speaking FMS patients. It does not require prior specific training, and can be used both clinical and in research to be carried out on FMS patients.

\section{Additional file}

Additional file 1: Spanish version of Revised Fibromyalgia Impact Questionnaire (FIQR).

\section{Abbreviations}

FMS: Fibromyalgia syndrome; FIQ: Fibromyalgia Impact Questionnaire; FIQR: Revised Fibromyalgia Impact Questionnaire; CRF: Case Report Form; HADS: Hospital Anxiety and Depression Scale; SF-36: Short Form of 36-Health Survey; PCS: Physical component summary of SF-36; MCS: Mental component summary of SF-36; PF: Physical functioning; PR: Physical role functioning; BP: Bodily pain; GH: General health perceptions; VT: Vitality; SF: Social role functioning; RE: Emotional role functioning; $\mathrm{MH}$ : Mental health; BPI: Brief Pain Inventory; SD: Standard deviation; ICC: Intraclass correlation coefficient; Cl: Confidence interval.

\section{Competing interests}

The authors declare that they have no competing interests.

\section{Authors' contributions}

JMGL and EPC designed the project and performed the Spanish translation of the FIQR. MS, JMGL, JH, and RM contributed to the acquisition of data. JB performed the statistical analysis. MS and EPC interpreted the results and drafted the manuscript. All authors read and approved the final manuscript.

\section{Acknowledgements}

The authors would like to acknowledge Fernando Rico-Villademoros for his comments that help to improve the manuscript, and also thank all fibromyalgia syndrome patients who participated in this study selflessly.

\section{Author details}

'Department of Neurosciences, University of the Basque Country UPV/EHU, Bilbao, Spain. ${ }^{2}$ Institute of Neurosciences, University of Granada, Granada, Spain. ${ }^{3}$ Spanish CIBER of Mental Health (CIBERSAM), Bilbao, Spain.

Received: 28 April 2013 Accepted: 25 July 2013

Published: 1 August 2013

\section{References}

1. Wolfe F, Smythe HA, Yunus MB, Bennett RM, Bombardier C, Goldenberg DL, Tugwell P, Campbell SM: The American College of Rheumatology. Criteria for the classification of Fibromyalgia. Report of the Multicenter Criteria Committee. Arthritis Rheum 1990, 33:160-172.

2. Collado A, Alijotas J, Benito P, Alegre C, Romera M, Sañudo I, Martín R, Peri JM, Cots JM: Documento de consenso sobre el diagnóstico y tratamiento de la fibromialgia en Cataluña. Med Clin (Barc) 2002, 118:745-749.

3. Burckhardt CS, Clark SR, Bennett RM: The Fibromyalgia Impact Questionnaire: development and validation. J Rheumatol 1991, 18:728-733.

4. Bennett R: The Fibromyalgia Impact Questionnaire (FIQ): a review of its development, current version, operating characteristics and uses. Clin Exp Rheumatol 2005, 23(Suppl 39):154-162.

5. Dunkl PR, Taylor AG, McConnell GG, Alfano AP, Conaway MR: Responsiveness of fibromyalgia clinical trial outcome measures. J Rheumatol 2000, 27:2683-2691.

6. Offenbacher M, Cieza A, Brockow T, Amann E, Kollerits B, Stucki G: Are the contents of treatment outcomes in fibromyalgia trials represented in the International Classification of Functioning, Disability, and Health? Clin J Pain 2007, 23:691-701.

7. Iversen MD: Fibromyalgia. The Fibromyalgia Impact Questionnaire (FIQ). Arthritis Rheum 2003, 49(Suppl 5):210-213.

8. Bennett RM, Firend R, Jones KD, Ward R, Han BK, Ross RL: The Revised Fibromyalgia Impact Questionnaire (FIQR): validation and psychometric properties. Arthritis Res Ter 2009, 11:R120.

9. Ediz L, Hiz O, Toprak M, Tekeoglu I, Ercan S: The validity and reliability of the Turkish version of the Revised Fibromylagia Impact Questionnaire. Clin Rheumatol 2011, 30:339-346.

10. Srifi N, Bahiri R, Rostom S, Bendeddouche I, Lazrek N, Hajjaj-Hassouni $\mathrm{N}$ : The validity and reliability of the Moroccan version of the Revised Fibromyalgia Impact Questionnaire. Rheumatol Int 2013, 33:179-183.

11. Calandre EP, Vilchez JS, Molina-Barea R, Tovar MI, García-Leiva JM, Hidalgo J, Rodríguez-López CM, Rico-Villademoros F: Suicide attempts and risk of suicide in patients with fibromyalgia: a survey in Spanish patients. Rheumatology 2011, 50:1889-1993.

12. Esteve-Vives J, Rivera Redondo J, Salvat Salvat MI, De Gracia Blanco M, Alegre De Miquel C: Propuesta de una versión de consenso del Fibromyalgia Impact Questionnaire (FIQ) para la población española. Reumatol Clin 2007, 3:21-24.

13. Zigmond AS, Snaith RP: The hospital anxiety and depression scale. Acta Psychiatr Scand 1983, 67:361-370.

14. Quintana JM, Padierna A, Esteban C, Arostegui I, Bilbao A, Ruiz I: Evaluation of the psychometric characteristics of the Spanish version of the Hospital Anxiety and Depression Scale. Acta Psychiatr Scand 2003, 107:216-221.

15. Ware JR, Sherbourne CD: The MOS 36-item short-form health survey (SF-36) (I). Conceptual framework and item selection. Med Care 1992, 30:473-489.

16. Vilagut G, Ferrer M, Rajmil L, Rebollo P, Permanyer-Miralda G, Quintana JM, Santed R, Valderas JM, Ribera A, Domingo-Salvany A, Alonso J: El Cuestionario de Salud SF-36: una década de experiencias y nuevos desarrollos. Gac Sanit 2005, 19:135-150.

17. Alonso J, Prieto L, Antó JM: La versión española del SF-36 Health Survey (Cuestionario de Salud SF-36): un instrumento para la medida de los resultados clínicos. Med Clin (Barc) 1995, 104:771-776.

18. Cleeland CS, Ryan KM: Pain assessment: global use of the Brief Pain Inventory. Ann Acad Med Singapore 1994, 23:129-138.

19. Mendoza T, Mayne T, Rublee D, Cleeland C: Reliability and validity of a modified Brief Pain Inventory short form in patients with osteoarthritis. Eur J Pain 2006, 10:353-361.

20. Badía X, Muriel C, Gracia A, Núñez-Olarte JM, Perulero N, Galvez R, Carulla J, Cleeland CS, y grupo Vesbpi: Validación española del cuestionario Brief 
Pain Inventory en pacientes con dolor de causa neoplásica. Med Clin (Barc) 2003, 120:52-59.

21. Shrout PE, Fleiss JL: Intraclass correlations: uses in assesing rater reliability. Psychol Bull 1979, 86:420-428.

22. De Vet HCW, Terwee CB, Mokkink LB, Knol DL: Measurement in medicine a practical guide. Cambridge: Cambridge University Press; 2011.

doi:10.1186/1477-7525-11-132

Cite this article as: Salgueiro et al: Validation of a Spanish version of the Revised Fibromyalgia Impact Questionnaire (FIQR). Health and Quality of Life Outcomes 2013 11:132.

\section{Submit your next manuscript to BioMed Central} and take full advantage of:

- Convenient online submission

- Thorough peer review

- No space constraints or color figure charges

- Immediate publication on acceptance

- Inclusion in PubMed, CAS, Scopus and Google Scholar

- Research which is freely available for redistribution 